\title{
EL CONCEPTO DE JUSTICIA EN RAWLS: UN ANÁLISIS DESDE EL CONTEXTO DE LA GLOBALIZACIÓN DE LA SOCIEDAD POSMODERNA Y LA INTERPRETACIÓN CONSTITUCIONAL EN COLOMBIA ${ }^{1}$
}

Justice's Concept in Rawls: An Analysis from Globalization Context of the Post-modern Society and the Constitutional Interpretation in Colombia

\section{Luisa Fernanda Hurtado Castrillón ${ }^{2}$}

Fecha de recepción: 31 de marzo de 2015

Fecha de aceptación: 12 de mayo de 2015

SUMARIO: 1. Introducción; 2. Una mirada desde el problema; 3. Avances preliminares de la investigación; 4. De los constructos de la teoría de la justicia; 4.1. De los principios de la justicia; 5. La justicia en el ámbito constitucional colombiano; 5.1. Primeros avances desde la identificación de la interpretación constitucional; 5.2. La justicia distributiva; 6. Conclusiones;

7. Referencias bibliográficas.

\footnotetext{
${ }^{1}$ El presente artículo es derivado de la investigación titulada Hacia una configuración de la justicia en el Estado Social de Derecho en Colombia: análisis desde la Teoría de la Justicia de John Rawls. Esta investigación fue financiada con recursos propios, y en su desarrollo la autora de este artículo actuó como investigadora principal.

2 Investigadora Junior Colciencias (2015), candidata a Doctora en Derecho de la Universidad Libre Sede Bogotá, Cohorte 2014. Directora del Centro de Investigaciones Socio Jurídicas de la Facultad de Derecho de la Universidad Libre Seccional Bogotá.
} 


\section{COMO SE CITA ESTE ARTÍCULO (APA 6)}

Hurtado Castrillón, Luisa Fernanda (2015). El concepto de justicia en Rawls: Un análisis desde el contexto de la globalización de la sociedad posmoderna y la interpretación constitucional en Colombia. Revista Jurídica Mario Alario D’Filippo, VII (14), pág 54-71.

\section{RESUMEN}

El presente artículo responde a las revisiones preliminares en el marco de la investigación Hacia una configuración de la justicia en el Estado Social de Derecho en Colombia: análisis desde la Teoría de la Justicia de John Rawls, en la cual se establecerán los principales elementos que constituyen la Teoría de la Justicia de John Rawls y el desarrollo jurisprudencial frente al concepto de Estado Social de Derecho, principios, valores constitucionales y justicia distributiva y social.

\section{PALABRAS CLAVE}

Estado Social de Derecho, igualdad, libertad, justicia distributiva.

\section{ABSTRACT}

This paper responds to preliminary reviews as part of the research: "Toward a Configuration of Justice in the Rule of Law in Colombia: Analysis from Theory of Justice by John Rawls" in which the main elements will be established constituting the Theory of Justice by John Rawls and jurisprudential development to the concept of rule of law, principles, constitutional values and distributive and social justice.

\section{KEYWORDS}

Social rule of law, equality, freedom, distributive justice. 


\section{INTRODUCCIÓN}

El presente artículo pretende dar una mirada inicial al concepto de justicia que se estableció en la estructura axiológica de la Constitución de 1991, desde la necesidad de establecer su importancia y aplicación desde la perspectiva teórica de John Rawls en su "Teoría de la Justicia".

La reflexión de orden investigativo pretende visibilizar el concepto de justicia planteado por Rawls con la base fundante de los principios de la justicia y los constructos de su teoría. De igual manera, se establecerá una aproximación a la inserción del concepto de justicia en el texto constitucional de Colombia en 1991, su trascendencia en el marco de la fórmula de constitución del Estado colombiano y seguirá con la interpretación que de éste establecimiento ha hecho la Corte Constitucional en dos iniciales jurisprudencias trascendentales, en una primera aproximación de construcción.

Este proceso reflexivo hace parte de la construcción del proyecto de investigación doctoral titulado Hacia una configuración de la justicia en el Estado Social de Derecho en Colombia: análisis desde la Teoría de la Justicia de John Rawls, que en la actualidad desarrolla la autora.

Esta propuesta investigativa pretende presentar, en un estadío superior de avance, un aporte en el conocimiento jurídico de orden constitucional frente a la determinación del concepto de justicia desde su configuración en el Estado Social de Derecho. Su pertinencia radica principalmente en la necesidad de determinar la forma cómo el constituyente de 1991 en Colombia concibió el acuerdo general de la justicia inmerso en la nueva fórmula estatal para la época y si ese establecimiento concuerda con los lineamientos de la Teoría de la Justicia de John Rawls.

\section{UNA MIRADA DESDE EL PROBLEMA}

La Constitución de 1991 en Colombia estableció una nueva configuración del Estado, consagrándolo bajo la fórmula de un Estado Social de Derecho, una adecuación a un estado democrático y constitucional, del cual se desprende el compromiso de reivindicar lo social para el pleno goce de las garantías constitucionales y de carácter universal, basados en principios fundantes con carácter normativo que permiten su plena vigencia, tal y como lo estableció la Corte Constitucional en Sentencia T-505 de 1992:

El carácter social de nuestro Estado de Derecho no es una fórmula retórica o vacía. Por el contrario, la naturaleza social que identifica al ordenamiento jurídico tiene clara expresión en la prevalencia de los derechos fundamentales, en la superación de la crisis del Estado de Derecho como sinónimo de la legalidad abstracta y en la inmediata realización de urgentes tareas sociales, todo lo anterior en desarrollo de los principios de solidaridad y dignidad humana. 
La dignidad humana y la solidaridad son principios fundantes del Estado social de derecho. Las situaciones lesivas de la dignidad de la persona repugnan al orden constitucional por ser contrarias a la idea de justicia que lo inspira. La reducción de la persona a mero objeto de una voluntad pública o particular (v.gr. esclavitud, servidumbre, destierro), los tratos crueles, inhumanos o degradantes (CP art. 12) o simplemente aquellos comportamientos que se muestran indiferentes ante la muerte misma (p. ej. el sicariato), son conductas que desconocen la dignidad humana y, en caso de vulneración o amenaza de derechos fundamentales, pueden ser pasibles de repulsa inmediata por vía de la acción de tutela, sin perjuicio de las acciones legales correspondientes.

El Estado constitucional democrático ha sido la respuesta jurídico-política derivada de la actividad intervencionista del Estado. Dicha respuesta está fundada en nuevos valoresderechos consagrados por la segunda y tercera generación de derechos humanos y se manifiesta institucionalmente a través de la creación de mecanismos de democracia participativa, de control político y jurídico en el ejercicio del poder y sobre todo, a través de la consagración de un catálogo de principios y de derechos fundamentales que inspiran toda la interpretación y el funcionamiento de la organización política (ARAGON REYES, 1989).

La justicia en el marco del Estado, permite concebir la forma misma de su organización, razón por la cual, está presente desde el momento mismo de su creación:

Preguntarse cómo debe vivir la gente, cómo deber ser una sociedad para ser justa, de qué manera se debe realizar la distribución y qué se debe distribuir, forman parte de los temas que estudió la filosofía en la antigüedad y de los problemas que se discuten especialmente a partir del siglo XX y que enfocan la cuestión de la inequidad (Britos, 2012).

La Teoría de la Justicia termina de redondear la crítica al utilitarismo que Rawls había emprendido 20 años atrás, cuando decide acoger la tradición contractualista como la más adecuada para concebir una concepción de justicia como equidad capaz de satisfacer por consenso las expectativas de igual libertad y justicia distributiva de la sociedad. Para ello concibe un procedimiento de consensualización, la posición original, de la que se derivan, en condiciones simétricas de libertad e igualdad argumentativas, unos principios de justicia que orientan la construcción institucional de la estructura básica de la sociedad, a nivel político, económico y social (RAWLS, Teoría de la Justicia, 1979).

Así las cosas, se plantea la presente investigación pretende dar respuesta al siguiente cuestionamiento: ¿Cuál es el concepto de Justicia desde el Estado Social de Derecho en Colombia desarrollado por la jurisprudencia de la Corte Constitucional a partir de la Teoría de la Justicia de John Rawls?

\section{AVANCES PRELIMINARES DE LA INVESTIGACIÓN}

¿A quién no interesa la justicia? La respuesta obvia sería que a la totalidad de los seres humanos, pues ella se encuentra presente en los actos cotidianos, en la vida familiar, laboral. Es decir, la justicia es un asunto de interés general. Pues bien, bajo esta premisa, 
se plantea la necesidad de traspasar el ámbito meramente personal e individual, para trasladarlo a la visión macro, a identificar desde lo general, desde la forma cómo la justicia opera en el marco del Estado, entendiendo éste como la forma válida de organización de los pueblos modernos, en un marco democrático.

El manejo de la justicia ha sido un asunto que ha interesado desde los comienzos mismos de la organización estatal. En la antigua Grecia, la justicia se convirtió en un tema de constante presencia en los discursos de los principales pensadores, desde Sócrates, Platón y en especial por Aristóteles, para quien la justicia es una virtud, que se construye desde el respeto por las leyes y la correcta distribución de los bienes sociales.

A lo largo de la historia de la humanidad, la justicia se ha presentado como una finalidad en las estructuras sociales organizadas como Estados democráticos, un ideal que sin tener una clara definición, se encuentra presente como objetivo vital.

La modernidad ha traído consigo no sólo los grandes avances tecnológicos, también la transformación de las sociedades y sus estructuras e instituciones. El planteamiento de la justicia como un principio innegable de los gobiernos democráticos, plantea de igual manera la gran pregunta hacia cómo hacer posible este principio, que no se remite únicamente a la función del poder público frente a las trasgresiones de los bienes jurídicos tutelados, sino en la justa proporción de la organización de los diferentes niveles sociales, un orden justo, equitativo que procure la prosperidad general.

Pero surge entonces la pregunta: “¿cuándo un orden es justo? Cuando regula la conducta de los hombres de una manera tal que a todos satisface y a todos permite alcanzar la felicidad" (Kelsen, 1991) Sin embargo esta simple explicación, sin interés de despreciar el concepto, conduce a otra gran cuestión y es el tema de la felicidad, desde la perspectiva del colectivo, cómo lograr que la estructura estatal determinada sea capaz de satisfacer a todos sus integrantes.

Frente a esto, Kelsen presenta la postura de Jeremy Bentham frente a la justicia:

Si la justicia es la felicidad, es imposible que exista un orden social justo si por justicia se entiende la felicidad individual. Pero un orden social justo es también imposible aún en el caso que este procure lograr, no ya la felicidad individual de todos, sino la mayor felicidad posible del mayor número posible (Kelsen, 1991).

De esta manera, se podría colegir que la estructuración de un orden social justo parte de la satisfacción del colectivo desde la visión objetiva y no como una satisfacción de orden individual subjetiva, pues de lo contrario, sería poco probable su efectiva realización. Queda entonces en suspenso, la manera de verificar la justicia desde el entorno estrictamente social, desde la enunciación de los postulados del bienestar general. 
La necesidad de identificar dichas formas, ha llevado a la reflexión desde lo teórico, pretendiendo esbozar las particularidades de la justicia, sus conceptos, su importancia, la forma de hacerla efectiva; grandes filósofos, politólogos, sociólogos, abogados, han pretendido dar respuesta a la misma pregunta sobre la justicia, sin que hasta el momento se pueda establecer una respuesta concreta.

En este punto, Ilega Rawls en 1971 -en medio de la crisis de la guerra fría y los mercados petrolíferos- reformulando el contrato social como punto de partida para estructurar un concepto de justicia basado en el acuerdo general y posicionado en dos principios estructurales. Esta base teórica ha tenido incluso, de parte de su autor, replanteamientos como el realizado a partir de La justicia como equidad, un replanteamiento, en 2001 . Su vigencia está intacta, el discurso planteado sigue siendo objeto de debate y aún más si el análisis se centra en el contexto latinoamericano, en especial, en el ámbito colombiano.

Uno de los principales elementos y fines de constitución de los estados constitucionales fue sin lugar a dudas la búsqueda por la implantación de regímenes democráticos justos, que permitieran la garantía efectiva de los derechos fundamentales individuales. Es así como la Justicia, se establece como el punto orientador de la labor estatal, procurándola no sólo en el marco de la administración de justicia como función pública, sino como un objetivo ulterior del Estado, que transversaliza todas sus funciones.

Es así como se materializa la necesidad, en el mundo moderno, de generar la discusión en torno a las teorías contractualistas de la conformación del Estado moderno y revisar su aplicación en las circunstancias que se presentaban en el mundo del siglo XX.

El resurgimiento de la filosofía política en la segunda mitad del siglo XX se origina, cronológicamente, con la publicación de la Teoría de la Justicia (1971) de John Rawls, cuyos planteamientos constituyen un audaz intento por fundamentar una nueva concepción de la moral, la política y el derecho, y de sus relaciones entre sí, con sustanciales connotaciones para el desarrollo institucional de la democracia e inaugurando con ello un proyecto alternativo, similar al de Habermas, que hoy se inscribe en lo que ha dado por llamarse democracia deliberativa (MEJÍA, 2005).

Es por tal razón que Rawls, en un primer momento, establece las bases de una teoría innovadora que retoma los clásicos teóricos contractualistas y define sus postulados a partir de los siguientes lineamientos que me permitiré resumir brevemente:

De acuerdo con Mejía Quintana (2005) la base del constructo teórico de Jhon Rawls, plantea una concepción de justicia como equidad capaz de satisfacer por consenso las expectativas de igual libertad y justicia distributiva de la sociedad.

El desarrollo de una Teoría de la Justicia se enmarca desde la estructura básica de la sociedad, principios como resultado de un acuerdo o contrato social, un acuerdo original 
entre todos los miembros, la forma de llegar a este acuerdo, sería el objeto central de la construcción teórica.

Rawls plantea tres perspectivas de la razón práctica, en tres momentos de un mismo proceso de construcción: el dialógico-moral que, con la figura de la posición original, supone la obtención de un consenso racional y argumentado donde todas las concepciones de justicia y sus proyecciones económicas son asumidas, contrastadas y discutidas; el político-contractual, donde la concepción política de justicia entra a fundamentar la posibilidad de consensos entrecruzados entre las concepciones omni-comprehensivas razonables de la sociedad y, a partir de ello, construir cooperativamente, el espacio de lo público; y, por último, el ético-contextual, a través del cual la persona, como miembro de una comunidad y tradición concretas y específicas, subsume o no los principios dentro de su irreductible e irrenunciable esfera privada individual (MEJíA, 2005).

\section{DE LOS CONSTRUCTOS DE LA TEORÍA DE LA JUSTICIA}

Rawls va a concebir un procedimiento de argumentación moral para garantizar que los principios de la justicia sean escogidos contractualmente, pero rodeando ese contrato de todas las garantías necesarias para que sea el de hombres racionales y morales que no contaminen con sus juicios egoístas la imparcialidad de los mismos (RAWLS, Teoria de la Justicia, 1979).

¿Qué es lo que hace justa o legítima a una sociedad? Para Rawls es el consenso imparcial, una "posición original" que permita reforma de la estructura de la sociedad y se establezca por el acuerdo sobre principios de forma imparcial. En efecto, el autor afirma que "(...) la posición original es el status quo inicial apropiado que asegura que los acuerdos fundamentales alcanzados en ella sean imparciales" (RAWLS, 1979).

Esta posición original requiere de seres humanos que no distinguen su posición socioeconómica en la sociedad y por tanto se encuentran desprovistos de parámetros comparativos que permitan generar juicios subjetivos frente a una posición de ventaja particular.

Rawls señala esta postura como el velo de ignorancia, mediante el cual no se identifica el perfil específico de su estatus al interior de la sociedad, permitiendo así la identificación de los principios de justicia. Mediante la posición original, se procuraría por la construcción de principios para una sociedad ideal, principios en igualdad de condiciones, con restricciones específicas y lógicas, manteniendo postulados universales como la libertad.

Para Rawls, la posición original y el velo de ignorancia constituyen la situación y el mecanismo que permiten que los principios de justicia satisfagan dos condiciones que los modelos contractualistas anteriores no habían logrado realizar: primero, garantizar 
plenamente el procedimiento y la base consensual del contrato social; y segundo, gracias a lo anterior y a las restricciones de información impuestas por el velo de ignorancia, imprimirle a la selección de los principios de la mayoría la legitimidad moral que evite cualquier asomo de arbitrariedad (MEJíA, 2005).

En este sentido, para Rawls los principios que estructuran la sociedad en circunstancias de la justicia son la presencia de unas condiciones de escases moderada y las demandas conflictivas ante la división de ventajas sociales. Para hacer efectiva la posición original en la constitución de principios de justicia en la sociedad, se plantea la Teoría de la elección racional: la cual permite la identificación de los principios de la justicia en un razonamiento bajo condiciones de incertidumbre.

La decisión sobre la construcción de principios de justicia al interior de una sociedad, se basa en estructurar los mismos bajo las siguientes condiciones: Generalidad, universalidad, de orden público, con un ordenamiento y de carácter definitivos.

El segundo constructo de la Teoría de la Justicia es la construcción de los denominados principios de la justicia:

Unos principios de la justicia desde los cuales se derive todo el ordenamiento social pero cuya selección garantice, primero, la necesidad racional de los mismos, segundo, su rectitud moral y, tercero, una base consensual que los legitime.

Los principios buscan regular la estructura básica de la sociedad y disponen la organización de los derechos y deberes sociales, así como los parámetros económicos que pueden regir a los individuos que la componen. El primer principio define el ordenamiento constitucional de la sociedad y el segundo la distribución específica del ingreso, riqueza y posibilidad de posición de los asociados (MEJÍA, 2005).

\subsection{DE LOS PRINCIPIOS DE LA JUSTICIA}

La base fundamental sobre el desarrollo de la Teoría de la Justicia se concreta en lo que el autor denomina "Principios de la Justicia", los cuales responden a una discusión consensual en escenarios previos de la posición original.

Los principios de la justicia procuran orientar la estructura básica de la sociedad; ahí radica su importancia, generando la identificación de derechos y deberes los cuales se resumen esquemáticamente en los siguientes elementos:

\section{Principio de libertad}

Todos con los mismos derechos de libertad, cualquiera que sea su forma. No se puede sacrificar bajo ninguna circunstancia. 


\section{Principio de igualdad de oportunidades - Principio de la diferencia}

Se configura bajo dos elementos:

- $\quad$ Igualdad de oportunidades económicas

- Desigualdad económica con beneficios a los menos aventajados.

Rawls plantea finalmente que los Principios de la Justicia son los siguientes:

\section{"Primer Principio}

Cada persona ha de tener un derecho igual al más amplio sistema total de libertades básicas, compatible con un sistema similar de libertad para todos.

\section{Segundo Principio}

Las desigualdades económicas y sociales han de ser estructuradas de manera que sean para:

a) mayor beneficio de los menos aventajados, de acuerdo con un principio de ahorro justo, $y$

b) unido a que los cargos y las funciones sean asequibles a todos, bajo condiciones de justa igualdad de oportunidades.

Primera Norma de Prioridad (La Prioridad de la Libertad)

Los principios de la justicia han de ser clasificados en un orden lexicográfico, y, por tanto, las libertades básicas sólo pueden ser restringidas en favor de la libertad en sí misma.

Hay dos casos:

a) una libertad menos extensa debe reforzar el sistema total de libertades compartido por todos;

b) una libertad menor que la libertad igual debe ser aceptada por aquellos que detentan una libertad menor.

Segunda Norma de Prioridad (La Prioridad de la Justicia sobre la Eficacia y el Bienestar) El segundo principio de la justicia es lexicográficamente anterior al principio de la eficacia, y al que maximiza la suma de ventajas; y la igualdad de oportunidades es anterior al principio de la diferencia. Hay dos casos:

a) la desigualdad de oportunidades debe aumentar las oportunidades de aquellos que tengan menos;

b) una cantidad excesiva de ahorro debe, de acuerdo con un examen previo, mitigar el peso de aquellos que soportan esta carga.

\section{Concepción general}

Todos los bienes sociales primarios -libertad, igualdad de oportunidades, renta, riqueza, y las bases de respeto mutuo-, han de ser distribuidos de un modo igual, a menos que una distribución desigual de uno o de todos estos bienes redunde en beneficio de los menos aventajados" (RAWLS, Teoría de la Justicia, 1979). 


\section{LA JUSTICIA EN EL ÁMBITO CONSTITUCIONAL COLOMBIANO}

En el año 1991, el contexto político, social y económico que atravesaba el país, influyó de manera certera para generar el cambio del texto constitucional, lo que no solo a la postre conllevó cambios en la estructura estatal, sino también en la concepción misma del Estado colombiano.

La fórmula del artículo primero de la Constitución, ampliada y respaldada a través de todo el texto fundamental, según la cual Colombia se define como un Estado social de derecho, es de una importancia sin precedentes en el contexto del constitucionalismo colombiano. Esta importancia amerita un pronunciamiento de la Corte sobre el alcance de este concepto y sobre su sentido e interpretación, no sólo en el contexto internacional -del cual sin duda alguna se nutrió la Asamblea Nacional Constituyente- sino en la Constitución misma, vista como una norma autónoma (Sentencia de Tutela, 1992).

La justicia hace presencia desde el preámbulo de la Constitución de 1991 y se ratifica en los artículos primero y segundo, configurado como un principio vital en el desarrollo de la estructura del Estado Social de Derecho vigente.

Dicha presencia sigue su recorrido a lo largo del texto constitucional respecto de las diferentes aristas que confluyen en el manejo de la justicia, sin embargo, el análisis de su concepto, de su trascendencia e importancia para la vigencia misma del Estado Social de Derecho, no es explícita, por tanto se infiere que dicho concepto haya sido desarrollado a la largo de la interpretación oficial que ha realizado la Corte Constitucional en su jurisprudencia.

\subsection{PRIMEROS AVANCES DESDE LA IDENTIFICACIÓN DE LA INTERPRETACIÓN CONSTITUCIONAL}

El desarrollo de la investigación, en su primera etapa, conlleva la identificación de jurisprudencia específica en el marco de la búsqueda del concepto de justicia, desde la interpretación que ha realizado la Corte Constitucional.

Así las cosas, en esta ponencia se resaltarán dos sentencias, consideradas "hitos" de la doctrina constitucional, para iniciar el análisis en la ubicación del concepto de justicia en el desarrollo constitucional a la luz del establecimiento de la fórmula del Estado Social de Derecho.

En estas dos jurisprudencias, la Corte Constitucional explica el significado del Estado Social de Derecho en tres grandes momentos:

Respecto del alcance del Estado Social de Derecho y su configuración, la Corte establece en primera medida, el significado de la configuración del Estado colombiano a partir de 
la Constitución de 1991 y de ahí esboza los alcances de los principios constitucionales y su amplio valor normativo. Interesa particularmente para efectos de los objetivos planteados en la investigación, la definición específica y explicación del Estado Social de Derecho, estructura sobre la cual se edifica el constructo de justicia:

\section{Sentencia T-406 de 1992 M.P Ciro Angarita Barón:}

6. La Constitución colombiana recoge ampliamente los postulados normativos del Estado social de derecho. Ello se comprueba no solo al repasar lo consagrado en la lista de los principios y de la Carta de derechos, sino también en la organización del aparato estatal. El artículo primero de la Constitución es la clave normativa que irradia todo el texto fundamental:

Art. 1. Colombia es un Estado social de derecho, organizado en forma de República unitaria, descentralizada, con autonomía de sus entidades territoriales, democrática, participativa y pluralista, fundada en el respeto de la dignidad humana, en el trabajo y la solidaridad de las personas que la integran y en la prevalencia del interés general.

Por lo menos tres postulados se desprenden del artículo primero:

a) El Estado es definido a través de sus caracteres esenciales. Entre estos caracteres y el Estado la relación es ontológica: El Estado Colombiano es tal, en tanto sus elementos esenciales están presentes; no se trata de cualidades, capacidades o dotes del Estado, sino de su propia naturaleza, de su propio ser.

b) Los caracteres esenciales del Estado tienen que ver no solo con la organización entre poderes y la producción y aplicación del derecho, sino también y de manera especial, con el compromiso por la defensa de contenidos jurídicos materiales. (PAREJO ALONSO, 1991)

El sentido y alcance del artículo primero no puede ser desentrañado plenamente a partir de una interpretación reducida al análisis de su texto. Cada una de las palabras del artículo posee una enorme carga semántica, la cual a través de la historia del constitucionalismo occidental, se ha ido decantando en una serie de nociones básicas que delimitan su alcance y lo hacen coherente y razonable. Una interpretación que se aparte del contexto nacional e internacional en el cual han tenido formación los conceptos del artículo primero, puede dar lugar a soluciones amañadas y contradictorias.

En síntesis, la Constitución está concebida de tal manera que la parte orgánica de la misma solo adquiere sentido y razón de ser como aplicación y puesta en obra de los principios y de los derechos inscritos en la parte dogmática de la misma. La carta de derechos, la nacionalidad, la participación ciudadana, la estructura del Estado, las funciones de los poderes, los mecanismos de control, las elecciones, la organización territorial y los mecanismos de reforma, se comprenden y justifican como transmisión instrumental de 
los principios y valores constitucionales. No es posible, entonces, interpretar una institución o un procedimiento previsto por la Constitución por fuera de los contenidos materiales plasmados en los principios y derechos fundamentales (Sentencia de Tutela , 1992).

Es así como la Corte Constitucional, en el año 1992, sienta las bases del alcance del Estado Social de Derecho, estableciendo que no sólo se refiere a los contenidos normativos descritos en el texto constitucional, sino que van más allá, generando la necesidad de ampliar el alcance normativo a los principios y valores contenidos en el desarrollo axiológico dogmático de la Constitución y que hacen efectivo la parte orgánica de la misma.

Respecto de los principios y valores constitucionales, la Corte Constitucional define entonces su inserción en los procesos interpretativos constitucionales, otorgándoles valor normativo:

\section{B. Principios y valores constitucionales}

7. Una de las características más relevantes del Estado social de derecho consiste en la importancia que adquiere el juez en sus relaciones con el legislador y con la administración. Buena parte de ella se deriva del nuevo papel que juegan los principios constitucionales en las decisiones judiciales y su relación con los valores y normas de la Carta.

a-. Los valores representan el catálogo axiológico a partir del cual se deriva el sentido y la finalidad de las demás normas del ordenamiento jurídico pueden tener consagración explícita o no; lo importante es que sobre ellos se construya el fundamento y la finalidad de la organización política.

De este tipo son los valores de convivencia, trabajo, justicia, igualdad, conocimiento, libertad y paz plasmados en el preámbulo de la Constitución. También son valores los consagrados en el inciso primero del artículo 20 de la Constitución en referencia a los fines del Estado: el servicio a la comunidad, la prosperidad general, la efectividad de los principios, derechos y deberes, la participación, etc. Todos ellos establecen fines a los cuales se quiere llegar. La relación entre dichos fines y los medios adecuados para conseguirlos, depende, por lo general, de una elección política que le corresponde preferencialmente al legislador. No obstante el carácter programático de los valores constitucionales, su enunciación no debe ser entendida como un agregado simbólico, o como la manifestación de un deseo o de un querer sin incidencia normativa, sino como un conjunto de propósitos a través de los cuales se deben mirar las relaciones entre los gobernantes y los gobernados, para que, dentro de las limitaciones propias de una sociedad en proceso de consolidación, irradien todo el tramado institucional.

Su condición de valores fundantes les otorga una enorme generalidad y, en consecuencia, una textura interpretativa abierta, dentro de la cual caben varias fijaciones del sentido. Corresponde al legislador, de manera prioritaria, la tarea de establecer la delimitación de dichos valores a través de leyes. En vista de su naturaleza abierta, los valores constitucionales sólo tienen una eficacia interpretativa; la Corte Constitucional debe ser respetuosa de la prerrogativa legislativa que consiste en establecer el alcance general de los mismos. 
Esto no impide que la Corte pueda, e incluso deba, en ciertos casos, valerse de ellos para resolver una situación específica o para valorar otras normas o instituciones; sin embargo, ello sólo sería posible dentro de una interpretación global de los hechos y del derecho y no como normas de aplicación inmediata suficientes por sí solas para fundamentar la decisión judicial. Los valores son definitorios a la hora de resolver un problema de interpretación en el cual está en juego el sentido del derecho, no son normas de aplicación directa que puedan resolver, aisladamente, un asunto.

b-. Los principios Constitucionales, a diferencia de los valores que establecen fines, consagran prescripciones jurídicas generales que suponen una delimitación política y axiológica reconocida y, en consecuencia, restringen el espacio de interpretación, lo cual hace de ellos normas de aplicación inmediata, tanto por el legislador como por el juez constitucional. Son principios constitucionales, entre otros, los consagrados en los artículos primero y tercero: el Estado social de derecho, la forma de organización política y territorial, la democracia participativa y pluralista, el respeto de la dignidad humana, el trabajo, la solidaridad, la prevalencia del interés general (artículo 1); la soberanía popular y la supremacía de la Constitución (artículo 2º). Ellos se refieren a la naturaleza política y organizativa del Estado y de las relaciones entre los gobernantes y los gobernados. Su alcance normativo no consiste en la enunciación de ideales que deben guiar los destinos institucionales y sociales con el objeto de que algún día se llegue a ellos; su valor normativo debe ser entendido de tal manera que signifiquen una definición en el presente, una base axiológico-jurídica sin la cual cambiaría la naturaleza misma de la Constitución y por lo tanto toda la parte organizativa perdería su significado y su razón de ser. Los principios expresan normas jurídicas para el presente; son el inicio del nuevo orden. Los valores, en cambio, expresan fines jurídicos para el futuro; son la mira que jalona hacia el orden del mañana.

Los principios fundamentales del Estado son una pauta de interpretación ineludible por la simple razón de que son parte de la Constitución misma y están dotados de toda la fuerza normativa que les otorga el artículo cuarto del texto fundamental. Sin embargo, no siempre son suficientes por sí solos para determinar la solución necesaria en un caso concreto. No obstante el hecho de poseer valor normativo, siguen teniendo un carácter general y por lo tanto una textura abierta, lo cual, en ocasiones, limita la eficacia directa de los mismos. En estos casos se trata de un problema relativo a la eficacia más o menos directa de los principios y no a un asunto relacionado con su falta de fuerza normativa. En síntesis, un principio constitucional jamás puede ser desconocido en beneficio de otra norma legal o constitucional o de otro principio no expresamente señalado en la Constitución, pero puede, en ciertos casos, necesitar de otras normas constitucionales para poder fundamentar la decisión judicial.

Los valores son normas que establecen fines dirigidos en general a las autoridades creadoras del derecho y en especial al legislador; los principios son normas que establecen un deber ser específico del cual se deriva un espacio de discrecionalidad legal y judicial. La diferencia entre principios y valores no es de naturaleza normativa sino de grado y, por lo tanto, de eficacia. Los principios, por el hecho de tener una mayor especificidad que los valores, tienen una mayor eficacia y, por lo tanto, una mayor capacidad para ser aplicados de manera directa e inmediata, esto es, mediante una subsunción silogística. Los valores, en cambio, tienen una eficacia indirecta, es decir, sólo son aplicables a partir de una concretización casuística y adecuada de los principios constitucionales. De manera similar, 
la diferencia entre principios y reglas constitucionales no es de naturaleza normativa sino de grado, de eficacia. Las normas, como los conceptos, en la medida en que ganan generalidad aumentan su espacio de influencia pero pierden concreción y capacidad para iluminar el caso concreto (Sentencia de Tutela , 1992).

De igual manera, la Corte en esta sentencia, sienta las bases de la construcción de un concepto de justicia desde el principio de igualdad material:

\subsection{LA JUSTICIA DISTRIBUTIVA}

En este punto, se vislumbra cómo la Corte Constitucional da sus primeras manifestaciones hacia la configuración de un concepto de justicia basado en principios de igualdad material y se logran identificar al menos dos principios de la Teoría de la Justicia de Rawls de manera incipiente:

\section{La justicia distributiva}

21. Ahora bien, la aceptación de la tutela para los derechos en cuestión, sólo cabe en aquellos casos en los cuales exista violación de un derecho fundamental de acuerdo con los requisitos y criterios de distinción antes anotados; sólo en estos casos, el juez puede, en ausencia de pronunciamiento del legislador, y con el fin de adecuar una protección inmediata del derecho fundamental, pronunciarse sobre el sentido y alcance de la norma en el caso concreto y, si es necesario, solicitar la intervención de las autoridades competentes para que tenga lugar la prestación del Estado que ponga fin a la violación del derecho.

22. Está claro que, en tales eventos el juez debe tomar decisiones que consulten no sólo la gravedad de la violación del derecho fundamental a la luz de los textos constitucionales, sino también las posibilidades económicas de solución del problema dentro de una lógica de lo razonable, que tenga en cuenta, por un lado, las condiciones de escasez de recursos y por el otro los propósitos de igualdad y justicia social que señala la Constitución. En la mayoría de estos casos, una vez establecida la violación de un derecho fundamental, el juez se enfrenta a un problema de justicia distributiva. Como se sabe, los elementos de juicio para definir este tipo de justicia no surgen de la relación misma entre los sujetos involucrados -el Estado y el ciudadano- sino que requieren de un criterio valorativo exterior a dicha relación (Aristóteles). La aplicación de los derechos económicos sociales y culturales plantea un problema no de generación de recursos sino de asignación de recursos y por lo tanto se trata de un problema político.

En ocasiones la norma constitucional proporciona este criterio. Así, por ejemplo, el artículo 366 es muy claro cuando afirma que en "los planes y presupuestos de la Nación y de las entidades territoriales, el gasto social tendrá prioridad sobre cualquier otra asignación". Sin embargo, es posible que ella no sea lo suficientemente iluminadora para resolver el caso sin llegar a consecuencias inaceptables o imposibles de llevar a cabo. En consecuencia, es necesario que el juez haga uso de la "lógica de lo razonable" de tal manera que la solución final que adopte sirva, ante todo, para proteger el derecho violado, y además tenga en cuenta las condiciones financieras de los entes públicos. Si fuese necesario dar elementos de juicio en abstracto sobre la justicia distributiva -cuestión de por si temeraria- 
se podría recurrir al principio de igualdad, ampliamente debatido en la teoría de la justicia de las últimas décadas, a partir del cual toda distribución de recursos, para ser justa, deba mejorar al menos la condición de los más desfavorecidos. Dicho en otra perspectiva, la justicia distributiva debe ser planteada como un problema de repartición -de asignación por parte del Estado- de recursos nuevos disponibles, cuyo resultado final, cualquiera que sean los beneficiarios o los afectados por tal repartición, no desmejore la situación de aquellos que poseen menos recursos. Esta interpretación, por lo demás se encuentra en plena armonía con lo prescrito en el artículo 13 inciso segundo:

"El Estado promoverá las condiciones para que la igualdad sea real y efectiva y adoptará medidas en favor de grupos discriminados o marginados.

"El Estado protegerá especialmente a aquellas personas que por su condición económica, física o mental, se encuentren en circunstancia de debilidad manifiesta y sancionará los abusos o maltratos que contra ellas se cometan".

23. Los reparos que pueda suscitar esta posición, en el sentido de que se llegaría a una enorme dispersión jurisprudencial en vista del carácter abiertamente político del contenido de las decisiones, pueden ser despejados si se tiene en cuenta la importante fuente de seguridad jurídica que se desprende del mecanismo de revisión de tutelas por parte de la Corte Constitucional y consagrado en el numeral 9 del artículo 241 de la Carta. Como se sabe, la revisión tiene, entre otras, la finalidad de servir de instrumento de fijación del sentido de los textos. Su alcance, por lo menos en términos prácticos, no se limita a la solución definitiva del caso que se presenta para su conocimiento, sino que va mucho más allá: sirve de pauta a todas las autoridades para la interpretación y aplicación de los derechos. Es innegable el valor pedagógico e incluso "normativo- general" de la jurisprudencia de tutela que crea la Corte Constitucional y su importancia y alcance apenas empiezan a vislumbrarse en el panorama jurídico nacional (Sentencia de Tutela , 1992).

\section{T-505 de 1992 M.P. Eduardo Cifuentes Muñoz:}

Sobre la Justicia Social, la Corte Constitucional ha establecido:

La justicia social no es un valor o ideal de libre apreciación por parte de los jueces constitucionales. Las concepciones de la comunidad y lo comúnmente aceptado como correcto o incorrecto son ejes referenciales para el enjuiciamiento y la determinación de lo razonablemente exigible. El juez constitucional no debe ser ajeno a las nociones de lo justo e injusto que tiene la opinión pública, más aún cuando la interpretación constitucional se apoya en los valores y principios consagrados en la Carta Política, bien para reconocerlos ora para promover su realización.

El Estado social de derecho mantiene el principio de legalidad, pero lo supera y complementa al señalar entre sus finalidades la de garantizar un orden político, económico y social justo (CP Preámbulo). La naturaleza social del Estado de derecho colombiano supone un papel activo de las autoridades y un compromiso permanente en la promoción de la justicia social.

La defensa de los valores supremos del ordenamiento obliga al Estado a intervenir - dentro del marco constitucional - para proteger a las personas en su dignidad humana y exigir la 
solidaridad social cuando ella sea indispensable para garantizar derechos fundamentales como la vida y la salud.

El principio de justicia distributiva según el cual en la asignación de los recursos económicos de una sociedad se deberá tender a privilegiar a los sectores desfavorecidos sirve de fundamento al régimen impositivo, a las reglas de elaboración presupuestal, a la jerarquización del gasto y a la fijación de prioridades en materia de prestación de los servicios públicos.

El Estado Social de Derecho, los principios de dignidad humana y de solidaridad social, el fin esencial de promover la prosperidad general y garantizar la efectividad de los derechos, deberes y principios constitucionales y el derecho fundamental a la igualdad de oportunidades, guían la interpretación de la Constitución económica e irradian todos los ámbitos de su regulación - propiedad privada, libertad de empresa, explotación de recursos, producción, distribución, utilización y consumo de bienes y servicios, régimen impositivo, presupuestal y de gasto público (Sentencia de Tutela, 1992) (Resaltado en negrilla fuera de texto).

\section{CONCLUSIONES}

Como parte del primer ejercicio de revisión doctrinal y jurisprudencial como avance investigativo, con ocasión de la presente ponencia, se puede concretar los siguientes puntos a manera de conclusión preliminar:

1. La Teoría de la Justicia de John Rawls, como referente teórico plantea el concepto de justicia como equidad, a partir de la democracia consensual la cual establece a la justicia social e imparcial como elemento fundamental de la estructura de una sociedad. El estandarte fundamental del soporte teórico es la defensa irrestricta de las libertades y el beneficio de orden económico entre los menos favorecidos bajo el principio de solidaridad.

Sobre este aspecto se debe profundizar en el desarrollo de la teoría, pues al tratarse de un análisis preliminar, quedaron faltando elementos indispensables para el desarrollo posterior de la misma, cuando el autor define la justicia desde la equidad.

2. La Corte Constitucional ha definido el contenido y alcance del desarrollo del concepto de Estado Social de Derecho en Colombia, la identificación de valores y principios con alcance normativo y el concepto primario de justicia distributiva y social.

La definición de Estado Social de Derecho se establece a partir de caracteres y elementos esenciales que configuran su auténtica razón de ser en la estructura constitucional. Estos elementos están constituidos por los Principios y Valores, a los cuales la Corte Constitucional les otorga alcance normativo, establecidos como pautas de interpretación. 
Respecto del concepto de Justicia Distributiva, la Corte Constitucional, en esta primera aproximación del desarrollo jurisprudencial concuerda en primera medida con los postulados planteados por Rawls respecto de la concepción de justicia en condiciones de igualdad a partir de la distribución equitativa de los recursos:

La justicia distributiva debe ser planteada como un problema de repartición -de asignación por parte del Estado- de recursos nuevos disponibles, cuyo resultado final, cualquiera que sean los beneficiarios o los afectados por tal repartición, no desmejore la situación de aquellos que poseen menos recursos (Sentencia de Tutela, 1992).

\section{REFERENCIAS BIBLIOGRÁFICAS}

ARAGON REYES, M. (1989). Constitución y Democracia. Madrid: Tecnos.

MEJÍA, Q. O. (2005). La filosofía política de John Rawls: la Teoría de la Jusitica de la tradición analítica a la tradición radical filosófico-política. En J. J. Botero, Con Rawls y contra Rawls. Bogotá, Colombia: Unibiblos Universidad Nacional de Colombia.

Britos, P. (2012). La justicia y el contrato social en Jhon Rawls. Bogota: Universidad Libre .

Castro Blanco, E., Rojas , H. D., \& Ruelle, A. (2012). Visiones de la Teoría de la Justicia de John Rawls. Bogotá, Colombia : Universidad Libre.

De la Calle, J. M. (2010). La justicia que necesita Colombia: diagnóstico y propuestas. Bogotá, Colombia: Legis S.A.

Kaufmann, A. (2006). Filosofía del Derecho. (L. V. Montoya, Trad.) Bogotá, Colombia : Universidad Externado de Colombia.

Kelsen, H. (1991). ¿Qué es la justicia? México DF: Distribuciones Fotamara.

Márquez, G. G. (Diciembre de 1982). The Nobel Prize in Literature 1982". Nobelprize.org. Nobel Media AB 2013. Obtenido de La soledad de América Latina: <http://www. nobelprize.org/nobel_prizes/literature/laureates/1982/>

Martinez, A. R. (2011). La interpretación democrática en el liberalismo igualitario de John Rawls. Telemática de Folosofía del Derecho, No. 14, 45-60.

Nussbaum, M. (2012). Las fronteras de la justicia: consideraciones sobre la exclusión. (R. V. Mosquera, Trad.) España: Paidós. 
Quinche Ramirez, M. F. (2009). Derecho constitucional colombiano: de la Carta de 1991 y sus reformas (Tercera ed.). Bogotá, Colombia: Universidad del Rosario.

PAREJO ALONSO, L. (1991). Constitución y valores del ordenamiento. En Estudios sobre la Constitución Española. Madrid: Civitas.

Rawls, J. (1971). Teoría de la Justicia . Cambrigde: The Belknap Press of Harvad University Press.

Rawls, J. (2012). La justicia como equidad: una reformulación . (E. Kelly, Ed., \& A. d. Francisco, Trad.) España: Paidós.

Sen, A. (2009). La idea de la Justicia. (H. V. Villa, Trad.) Bogotá, Colombia : Taurus.

Sentencia de Tutela, T-406 (Corte Constitucional 1992).

Sentencia de Tutela, T-505 (Corte Constitucional 1992). 